\title{
Development of LC-IMS-CID-TOFMS Techniques: Analysis of a 256 Component Tetrapeptide Combinatorial Library
}

\author{
Amy E. Hilderbrand, Sunnie Myung, Catherine A. Srebalus Barnes,* \\ and David E. Clemmer \\ Department of Chemistry, Indiana University, Bloomington, Indiana, USA
}

Recent improvements in ion mobility/time-of-flight mass spectrometry techniques have made it possible to incorporate nano-flow liquid chromatography and collision induced dissociation techniques. This combination of approaches provides a new strategy for detailed characterization of complex systems- such as, combinatorial libraries. Our work uses this technology to provide a detailed analysis of a tetrapeptide library having the general form $\mathrm{Xxx}_{1}-\mathrm{Xxx}_{2}-\mathrm{Xxx}_{3}-$ $X x_{4}$ where $X x_{1}=$ Glu, Phe, Val, Asn; $X x_{2}=$ Glu, Phe, Val, Tyr; $X x x_{3}=$ Glu, Phe, Val, Thr; and $\mathrm{Xxx}_{4}=\mathrm{Glu}$, Phe, Val, Leu-a system that is expected to contain 256 different peptide sequences. The results corroborate the presence of many expected peptide sequences and indicate that some synthetic steps appear to have failed. Particularly interesting is the observation of a t-butyl protecting group on the tyrosine (Tyr) residue. It appears that most Tyr containing peptides that have this t-butyl group attached favor formation of $[2 \mathrm{M}+2 \mathrm{H}]^{2+}$ dimers, which can be readily distinguished from $[\mathrm{M}+\mathrm{H}]^{+}$monomers based on differences in their gas-phase mobilities. In this case, we demonstrate the use of the mobility differences between $[2 \mathrm{M}+2 \mathrm{H}]^{2+}$ and $[\mathrm{M}+\mathrm{H}]^{+}$ions as a signature for a failure of a synthetic step. (J Am Soc Mass Spectrom 2003, 14, 1424-1436) (c) 2003 American Society for Mass Spectrometry

$\mathrm{A}$ remarkable feature of mix and split synthetic strategies on solid supports is the ability to create mixtures of extraordinary complexity [1]. With such complex systems, however, comes a tradeoff in the level of detail to which the individual components are characterized. Specifically, if a synthetic step fails unexpectedly, the purity of an entire class of desired molecules may be compromised. With this in mind, a number of strategies for characterizing complex libraries are being developed [2]. Among the most powerful of these is the combination of separation techniques such as liquid chromatography (LC) with mass spectrometry (MS). The advent of electrospray ionization (ESI) [3] allows LC to be coupled with MS in an online fashion. The LC separation simplifies the complex mixture and MS can be used for identification; that is, it is possible to select an initial precursor ion and utilize collision induced dissociation (CID) data to obtain structural information about individual components-an overall LC-MS/MS approach.

Although it is clear that LC-MS/MS provides a

Published online October 27, 2003

Address reprint requests to Dr. D. E. Clemmer, Department of Chemistry, Indiana University, Bloomington, IN 47405, USA. E-mail: clemmer@indiana.edu

*Current address: Eli Lilly and Co., Indianapolis, IN 46285, USA. means of checking for the existence of specific components within a library, this approach begins to break down as a global strategy for characterizing complicated libraries. One problem that emerges involves the initial MS selection. Libraries are complex and can have many components that elute from the LC column at the same time. Thus, while specific ions from some components are being selected for fragmentation analysis other components eluting at the same time are often discarded (remaining unanalyzed). Additionally, combinatorial libraries present a challenge for MS because of mass-to-charge ratio $(\mathrm{m} / \mathrm{z})$ degeneracies that arise for isomeric components [4]. Consider for example, a simple mixture of three four-residue peptide sequence isomers (Glu-Val-Val-Leu, Val-Glu-Val-Leu, and ValVal-Glu-Leu). One might expect that initial $\mathrm{m} / \mathrm{z}$ selection of these three isomers could be resolved based on fragmentation data-especially since accurate fragmentation pathways for peptides can often be predicted [5]. Table 1 lists the anticipated $b$ - and $y$-type ions that are expected upon fragmentation of these three isomers. In this system, the existence of the Glu-Val-Val-Leu (EVVL) peptide can be unambiguously established based on the observation of peaks at $m / z=130.0$ and 330.2, which correspond to the $\mathrm{E}\left(\mathrm{b}_{1}\right)$ and VVL $\left(\mathrm{y}_{3}\right)$ fragments; the presence of Val-Val-Glu-Leu (VVEL) can be established if peaks at $m / z=199.1$ and 261.1, 
Table 1. Expected fragment ions for the EVVL, VEVL, and VVEL sequence isomers

\begin{tabular}{|c|c|c|c|c|}
\hline Fragment & $m / z^{a}$ & $E V_{V} L^{b}$ & VEVL $^{b}$ & VVEL $^{b}$ \\
\hline$V\left(b_{1}\right)$ & 100.1 & & expected & expected \\
\hline$E\left(b_{1}\right)$ & 130.1 & unique & & \\
\hline$L\left(y_{1}\right)$ & 132.1 & expected & expected & expected \\
\hline $\mathrm{VV}\left(\mathrm{b}_{2}\right)$ & 199.1 & & & unique \\
\hline $\mathrm{EV}\left(\mathrm{b}_{2}\right)$ & 229.1 & expected & expected & \\
\hline $\operatorname{VL}\left(y_{2}\right)$ & 231.2 & expected & expected & \\
\hline$E L\left(y_{2}\right)$ & 261.1 & & & unique \\
\hline $\operatorname{VEV}\left(b_{3}\right)$ & 328.2 & expected & expected & expected \\
\hline $\operatorname{VVL}\left(\mathrm{y}_{3}\right)$ & 330.2 & unique & & \\
\hline $\operatorname{VEL}\left(y_{3}\right)$ & 360.2 & & expected & expected \\
\hline
\end{tabular}

${ }^{a} \mathrm{~m} / \mathrm{z}$ values correspond to calculated monoisotopic values calculated according to reference 5 .

${ }^{b}$ Representation of which fragments are expected (and should lead to unique assignment) for the EVVL, VEVL, and VVEL sequences. Note that although six b-and $y$-type ions are expected for the VEVL sequence, none of these fragment ions is unique for this set of isomers.

(corresponding to the $\mathrm{VV}\left(\mathrm{b}_{2}\right)$ and $\mathrm{EL}\left(\mathrm{y}_{2}\right)$ fragment ions, respectively) are observed. However, there are no fragment ions that are unique to the Val-Glu-ValLeu (VEVL) sequence. This example shows that in unfavorable cases, even simple combinations of peptides complicate the ability to provide detailed characterizations.

During the last few years our group has worked to incorporate an additional gas-phase dimension of separation for library characterization [6-9], based on ion mobility spectrometry [10]. The mobility of an ion through a buffer gas depends on the ion's collision cross section (which is related to its average shape) and net charge [11]. For ions of the same charge state, compact ions have higher mobilities than elongated ions [12]. For ions having the same collision cross section, more highly-charged species have higher mobilities than lower charge states [13]. This approach has been used by a number of groups to separate an array of different analyte types as well as to characterize the structures of different types of ions [14]. Several years ago Hill's group showed that different sequence isomers (for example Gly-Arg-Gly-Asp-Ser and Ser-Asp-Gly-ArgGly) could be separated based on differences in their gas phase mobilities [15]. We have shown that it is possible to separate many different isomer types, including sequence-, structural- and stereo-isomers. ${ }^{6} \mathrm{~A}$ key aspect of the separation is simply that different isomers establish different conformations (having different collision cross sections) in the gas phase.

Although the rapid separation of different isomers by IMS-MS approaches is possible, the ability to rapidly assign different peaks found across complex libraries to specific isomers is currently limited. One approach for the identification of isomers has been to compare experimentally measured mobilities with values that are calculated for trial conformations generated by theory [12]. Although this approach is useful and holds great promise, it is time intensive, primarily because highlevel theory is required to generate low-energy trial conformations. A simple approach that would complement mobility measurements and calculations for the identification of isomers is to record collision-induced fragmentation patterns for mobility separated ions. In favorable cases, even a few fragments would narrow down the number of possible isomers that would need to be considered by theory.

Until recently, the combination of IMS with CID-MS and LC has been limited by the formidable problem of the relatively low sensitivity of IMS measurements. IMS signals are limited by the low duty cycles associated with the initiation of mobility experiments as well as relatively low transmission of ions through a drift tube. In the last couple of years, we have incorporated several types of ion traps for improving the experimental duty cycle $[16,17]$ and developed a simple non-linear focusing field for increasing ion transmission through the drift tube [18]. With these improvements we can now carry out IMS-CID-MS measurements in combination with LC on complex mixtures.

This paper presents the first demonstration of an LC-IMS-CID-MS analysis of a combinatorial library-a mixture that is expected to contain 256 different tetrapeptide sequences, having the general form $\mathrm{Xxx}_{1}$ $\mathrm{Xxx}_{2}-\mathrm{Xxx}_{3}-\mathrm{Xxx}_{4}$ where $\mathrm{Xxx_{1 }}=$ Glu, Phe, Val, Asn; $\mathrm{Xxx}_{2}$ $=$ Glu, Phe, Val, Tyr; $X x_{3}=$ Glu, Phe, Val, Thr; and $\mathrm{Xxx}_{4}=\mathrm{Glu}$, Phe, Val, Leu. The system was designed in order to create a range of complexity associated with sequence isomers. We calculate that there should be only 104 unique masses. Of these, 46 peptides have no sequence isomer counterparts, and within these 46 only 27 are not isobaric with other peptides in the library. There are 58 different sets of sequence isomers: 18 sets of two; 24 sets of three; six sets of four; seven sets of six; and, three sets of 12 . Overall, the results make it possible to unambiguously confirm that most expected components are present. An unexpected outcome of the analysis is the observation of a series of doubly-charged dimer ions $\left([2 \mathrm{M}+2 \mathrm{H}]^{2+}\right)$ which appear to be favored for Tyr-containing peptides which have a t-butyl protecting group due to a failure in the deprotection step of the synthesis. These ions are easily identified based on their unique position in the mobility distribution.

\section{Experimental}

\section{Synthesis of a 256 Component Tetrapeptide Library}

A 256 component peptide library of the following sequence: $\mathrm{NH}_{2}-\mathrm{Xxx}_{1}-\mathrm{Xxx}_{2}-\mathrm{Xxx}_{3}-\mathrm{Xxx}_{4}-\mathrm{CO}_{2} \mathrm{H}$ (where $\mathrm{Xxx}_{1}=$ Glu, Phe, Val, Asn; $\mathrm{Xxx}_{2}=$ Glu, Phe, Val, Tyr; $\mathrm{Xxx}_{3}=$ Glu, Phe, Val, Thr; and $\mathrm{Xxx}_{4}=$ Glu, Phe, Val, Leu) was synthesized using standard solid-phase mix and split protocol [19] with fluorenylmethoxycarbonyl (Fmoc) peptide chemistry [20]. The C-terminal peptide positions were randomized by combining equal molar quantities of Fmoc-Leu-Wang, Fmoc-Val-Wang, FmocPhe-Wang and Fmoc-Glu(OtBu)-Wang resins (Nova- 
biochem, San Diego, CA). The resins were mixed in a nitrogen agitated reaction vessel with dimethylformamide (DMF) prior to the removal of the $\mathrm{N}$-terminal Fmoc protecting group with 20\% piperidine in DMF. The resulting resin mixture was split into four equal portions and placed into separate reaction vessels for the addition of the next amino acid residue. Amino acid coupling reactions were performed by the addition of pre-activated benzotriazol-1-yloxy (OBt) esters of each amino acid being added to the Fmoc-deprotected resin. Activated amino acid OBt esters were generated by reaction of the Fmoc amino acids (4.0 equivalents) with 2-(1-H-benzotriazol-1-yl)-1,1,3,3-tetramethyluronium hexafluorophosphate (HBTU) (3.9 equivalents), and 0.4 $\mathrm{M} \mathrm{N}$-methylmorpholine in DMF (4 equivalents) to the reaction vessel containing the resin. Quantitative ninhydrin reactions were used to assess the coupling efficiencies following each coupling reaction [21]. Following the completion of the amino acid couplings, the four resin fractions were combined and the Fmoc protecting groups of the amino acid residues were removed, in order to prepare the resin for the next coupling. Subsequent amino acid residues were added using the procedure outlined above. The amino acid residues used in this synthesis were: $\mathrm{N}-\alpha-\mathrm{Fmoc}-\mathrm{N}-\beta-$ trityl-L-Asn, $\mathrm{N}-\alpha$-Fmoc-L-Glu $\gamma$-tert-butyl ester, $\mathrm{N}-\alpha$ Fmoc-L-Phe, N- $\alpha$-Fmoc-O-tert-butyl-L-Thr, N- $\alpha$-FmocO-tert-butyl-L-Tyr, N- $\alpha$-Fmoc-L-Val (Novabiochem, San Diego, CA).

After coupling the final N-terminal amino acid residues, the Fmoc protecting group was removed. A trifluoroacetic acid (TFA)/phenol/water/thioanisole/ ethanedithiol solution (82.5:5:5:5:2.5 by volume) was added to cleave the library peptides from the solidphase support and remove side chain protecting groups. The resin was filtered from the solution and the peptides were precipitated in ether. The precipitate was washed several times with ether, dried, dissolved in an aqueous solution (30\% acetic acid) and lyophilized.

\section{Protocol for LC-IMS-CID-TOFMS Analysis of Library}

A Nanoflow-LC system (LC Packings, San Francisco, CA) coupled to the electrospray ionization source of a home-built injected-ion geometry IMS-CID-TOF instrument was used to analyze this library. Detailed descriptions of the instrument and other experiments have been given elsewhere $[17,22]$. A brief description of the experimental apparatus and overall procedure is given here. The overall experimental sequence is as follows. A $1.0 \mu \mathrm{L}$ aliquot of a $0.5 \mathrm{mg} \cdot \mathrm{mL}^{-1}$ tetrapeptide library in a 99:1 percent water:formic acid solution was injected onto a reverse phase $75 \mu \mathrm{m} \times 15 \mathrm{~cm}$ nano column packed with $3 \mu \mathrm{m}, 100 \AA$ pore size C18 (PepMap). A mobile phase mixture of $0.1 \%$ formic acid in water and $0.1 \%$ formic acid in acetonitrile ( $\mathrm{ACN}$ ) was used and the following gradient was employed: from 0 to $10 \mathrm{~min}$ (the mobile phase contained $0 \% \mathrm{ACN}$ ); from $10-15 \mathrm{~min}$ ( 0 to $5 \%$ ACN was used), $15-80 \mathrm{~min}$ ( 5 to $30 \% \mathrm{ACN}$ ), $80-85$ $\min (30$ to $40 \% \mathrm{ACN}$ ), $85-90 \mathrm{~min}(40$ to $100 \% \mathrm{ACN}$ ), and 90-95 $\min (100 \% \mathrm{ACN})$. The flow rate in this system was $180 \mathrm{~nL} \cdot \mathrm{min}^{-1}$. The gradient was held for $10 \mathrm{~min}$ at $0 \% \mathrm{ACN}$ to allow for the sample to be loaded onto the column. The eluent from the column is introduced into and nanosprayed from a $20 \mu \mathrm{m}$ PicoTip emitter TaperTip with P200P coating (New Objective, Inc., Woburn, MA). The electrosprayed peptide ions are extracted into a low-pressure vacuum chamber and are accumulated in an octopole ion trap. ${ }^{17}$ The accumulated packet of ions is then pulsed into an injected-ion mobility drift tube where the ions are separated based on differences in their mobilities through a helium buffer gas. The drift tube is $50.3 \mathrm{~cm}$ long and was operated using an electric field of $6.0 \mathrm{~V} \cdot \mathrm{cm}^{-1}$ and a He pressure of 1.5 torr at room temperature. Ions that exit the drift tube are focused into an octopole collision cell that can be filled with a gas $\left(\sim 10^{-4}\right.$ torr of $\mathrm{Ar}$ in these studies). For experiments where we wish to generate CID data, ions are accelerated to a desired energy and then injected into the gas-filled octopole collision cell; in other experiments where it is desirable to examine precursor ions the collision gas is removed from the cell. Upon exiting the collision cell, ions enter the source region of a reflectron geometry TOF mass spectrometer where high-frequency, high-voltage potentials are used to initiate measurements of flight times (and hence $\mathrm{m} / \mathrm{z}$ ratios).

\section{Nomenclature for Nested Measurements}

A key consideration in the understanding of this technique is that flight times in the evacuated flight tube of the mass spectrometer are much shorter than drift times through the drift tube and drift times are much shorter than retention times through a chromatographic system. Thus, it is possible to record flight time distributions within individual windows of the drift time distribution and distributions of drift times within individual windows of LC retention time. We refer to this type of analysis as a nested experiment and used the following nomenclature, $t_{R}\left[t_{D}\left(t_{F}\right)\right]$, where $t_{R}$ is LC retention time (which we denote in either seconds, minutes or frames), $t_{D}$ is the drift time in ms and $t_{F}$ is flight time in $\mu \mathrm{s}$. In the datasets described below (which have been recorded multiple times) individual $t_{D}\left(t_{F}\right)$ frames within the three dimensional $t_{R}\left[t_{D}\left(t_{F}\right)\right]$ dataset were each acquired for $2.5 \mathrm{~s}$ and the data were recorded over a total LC run time of $\sim 95 \mathrm{~min}$; each dataset that is discussed below contains a total of $\sim 2200 t_{D}\left(t_{F}\right)$ frames.

\section{Comparison of Different Datasets}

It is also important to note that the comparison of datasets can be done based on the arrival of specific peaks in any one of the dimensions. For experiments that are recorded in a back-to-back fashion, individual 
peaks in different LC-runs usually vary by only a few frames across any two datasets; in some cases, noticeably larger frame shifts are observed [usually not more than 20 frames (50s)]. The measured drift times between any two experiments are very reproducible. Usually any two drift time measurements differ by less than $1 \%$ (relative uncertainty) between two LC runs; this value is lower between frames within the same run. Flight-time measurements are converted to $\mathrm{m} / \mathrm{z}$ values using a simple multipoint calibration.

\section{Parallel Fragmentation of Ions}

Finally, we note that the LC-IMS-CID-MS experiment makes it possible to examine fragmentation patterns for many ions in parallel. This approach is feasible because CID is introduced after the mobility separation. Thus, all fragments and precursor ions are coincident in drift time [23]. Within the dataset all fragments and precursors are also coincident in $t_{R}$. In most cases within this dataset it is relatively straight forward to employ the parallel fragmentation approach. One aspect of this measurement that is important is that the CID event happen quickly (usually we aim for $<20 \mu \mathrm{s}$, within an individual drift time window). This condition is met by using relatively low target gas pressures and relatively high accelerating potentials. A detailed discussion of shifts that can occur has been given [24].

\section{Results and Discussion}

\section{Overview of Precursor Ion Distribution Analysis}

As described above, as components elute from the nanoLC column they are electrosprayed into the IMS-MS instrument for analysis. When no collision gas is employed in the octopole collision cell, this process leads to a dataset that corresponds primarily to precursor ions. It is useful to begin the discussion of one complete $t_{R}\left[t_{D}\left(t_{F}\right)\right]$ precursor ion dataset [which comprises more than 2000 nested $t_{D}\left(t_{F}\right)$ frames] by discussing a few frames in detail. Overall, this system behaves similarly to others that we have studied. Of particular interest is evidence for formation of multiply-charged tetrapeptide multimers. The assignments of groups of peaks as multiply-charged multimer ions relies on the more detailed work that we have done on simpler (one component) systems in the past [25, 26]. Below, we follow the same basic protocol as was used in the earlier work in order to assign groups of multimers.

\section{Typical Nested $t_{D}\left(t_{F}\right)$ Data Frames Within the Precursor Ion $t_{R}\left[t_{D}\left(t_{F}\right)\right]$ Dataset}

Figure 1 shows three example $t_{D}\left(t_{F}\right)$ datasets (frames 600,800 , and 1000) that were each acquired for $2.5 \mathrm{~s}$ across the LC separation. The flight times have been converted to $\mathrm{m} / \mathrm{z}$ ratios for simplicity. Several interesting features are immediately apparent in these data.
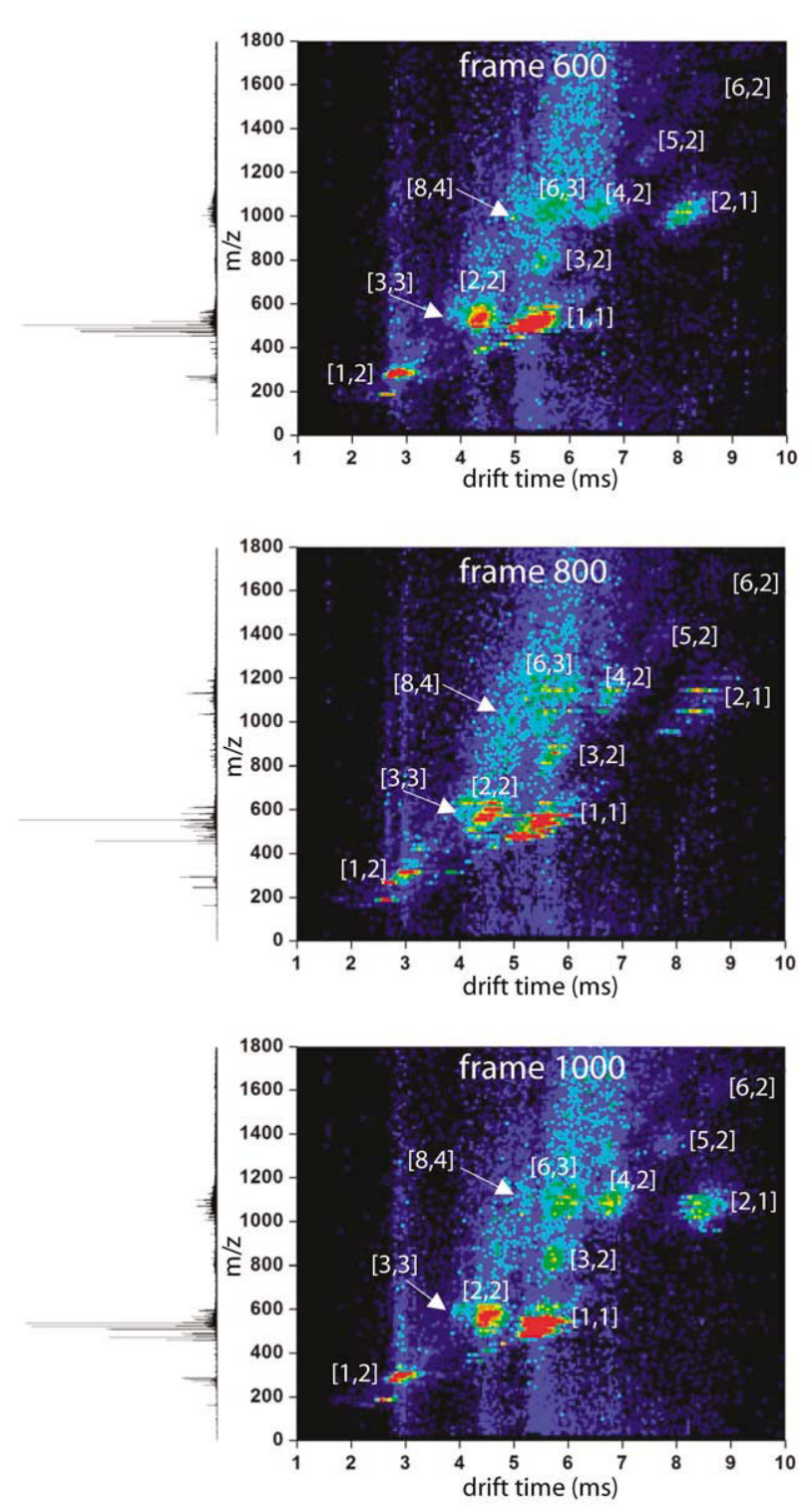

Figure 1. Three $t_{D}\left(t_{F}\right)$ plots from the precursor ion $t_{R}\left[t_{D}\left(t_{F}\right)\right]$ dataset showing multimer formation of eluting peptides. Frame $600\left(t_{R}=25.2 \mathrm{~min}\right), 800\left(t_{R}=33.6 \mathrm{~min}\right)$, and $1000\left(t_{R}=42 \mathrm{~min}\right)$ all show that multimers from the plus one monomer to the plus four octomer are present in the precursor ion data. The nomenclature $[\mathrm{m}, \mathrm{n}]$ where $\mathrm{m}$ is the number of monomer units and $\mathrm{n}$ is the charge, is used to label the multimers. Note that although several components are eluting at the same time, the distribution of multimers formed is not always statistical, indicating that special combinations of peptides preferentially form specific multimers or that varying concentrations of the components eluting in a particular frame only allow for multimers to form of only the components that are in the highest abundance.

First, peaks appear to fall into clusters that occur within narrow regions of drift times and $m / z$ ranges. The most abundant cluster of peaks in all three example $t_{D}\left(t_{F}\right)$ frames is found from drift times of $\sim 4.5$ to $6 \mathrm{~ms}$ and $\mathrm{m} / \mathrm{z}$ values ranging $\sim 400$ to 600 . These drift times and $\mathrm{m} / \mathrm{z}$ values are consistent with the formation of groups of singly-charged tetrapeptides $\left([\mathrm{M}+\mathrm{H}]^{+}\right.$monomer ions) that are expected to be present in the library. 
Another high-intensity group of peaks in all three frames is found in the drift time range of $\sim 2.0$ to $3.5 \mathrm{~ms}$ and have $\mathrm{m} / \mathrm{z}$ values ranging from $\sim 190$ to 300 . These ions can be assigned to groups of tetrapeptides that are doubly-charged during the electrospray process ([M + $2 \mathrm{H}]^{2+}$ monomers). Again, a comparison of calculated $m / z$ values for $[\mathrm{M}+2 \mathrm{H}]^{2+}$ states of expected peptides shows that specific peaks can often be associated with several different expected peptide sequences within groups of isomers. Thus, the overall comparison of the $[\mathrm{M}+\mathrm{H}]^{+}$and $[\mathrm{M}+2 \mathrm{H}]^{2+}$ data with calculated $\mathrm{m} / \mathrm{z}$ values for expected peptides indicated that the synthesis has basically proceeded as expected for most components.

\section{Evidence for Groups of Multiply-Charged Multimers of Tetrapeptides}

An interesting aspect of these data is the observation of additional groups of low-intensity peaks. The similarity of components in this mixture (all tetrapeptides) makes it possible for us to assign these groups into general families of tetrapeptide clusters of varying size and charge state. One group that is clearly apparent in each of the three example frames that are shown, corresponds to formation of doubly-charged tetrapeptide dimers ions $\left([2 \mathrm{M}+2 \mathrm{H}]^{2+}\right.$ species). In this case, the range of $\mathrm{m} / \mathrm{z}$ values $\sim 415$ to 625 is similar to the range observed for the $[\mathrm{M}+\mathrm{H}]^{+}$ monomers; thus we utilize the higher-mobilities (values of $t_{D}$ ranging from $\sim 4.2$ to $4.7 \mathrm{~ms}$ ) of these ions to assign this family as we have done previously for much simpler systems (usually a solution containing a single peptide). In addition, frames 600,800 , and 1000 also show evidence for an additional group of ions having $\mathrm{m} / \mathrm{z}$ values between 400 and 600; these ions can be resolved from other groups in this $\mathrm{m} / \mathrm{z}$ range because they have higher mobilities (shorter drift times, between 3.8 and $4.2 \mathrm{~ms}$ ) than the groups of $[\mathrm{M}+\mathrm{H}]^{+}$or $[2 \mathrm{M}+2 \mathrm{H}]^{2+}$ ions. The low-intensity group of peaks is consistent with formation of a family of tetrapeptide trimers ( $[3 \mathrm{M}+3 \mathrm{H}]^{3+}$ species).

Considerations of the $\mathrm{m} / \mathrm{z}$ ranges and drift times for other low-abundance groups of peaks allow these ions to also be assigned. The three example $t_{D}\left(t_{F}\right)$ frames that are displayed in Figure 1 show evidence for $[\mathrm{mM}+$ $\mathrm{nH}]^{\mathrm{n}+}$ clusters having as many as $\mathrm{m}=8$ subunits and $\mathrm{n}=4$ charges. We note that the appearance of these clusters across this spectrum is highly variable. In some instances groups of cluster peaks are found in broad distributions with intensities that suggest that they are formed in a statistical (random) fashion. In other regions of the dataset, sharp peaks dominate the cluster distribution. In these cases it appears that favorable interactions between specific sequences may enhance cluster formation.
Table 2. Identification of non isobaric/non sequence isomers

\begin{tabular}{lcccc}
\hline Peptide & Frame number & Drift time $(\mathrm{ms})$ & $\mathrm{m} / \mathrm{z}^{\mathrm{a}}$ & $\mathrm{m} / \mathrm{z}^{\mathrm{b}}$ \\
\hline \hline NEEE & 183 & 5.01 & 520.2 & 520.2 \\
EEEE & 183 & 5.01 & 535.2 & 535.2 \\
EYEE & 264 & 5.36 & 569.1 & 569.2 \\
NETL & 354 & 4.97 & 476.2 & 476.2 \\
NEEL & 367 & 5.27 & 504.2 & 504.2 \\
NVTV & 370 & 4.79 & 432.3 & 432.2 \\
EETL & 405 & 5.27 & 491.3 & 491.2 \\
EEEL & 437 & 5.27 & 519.3 & 519.2 \\
VVTV & 480 & 4.75 & 417.3 & 417.3 \\
NVVV & 495 & 4.88 & 430.3 & 430.3 \\
NYTV & 536 & 5.23 & 496.2 & 496.2 \\
VVVV & 576 & 4.79 & 415.3 & 415.3 \\
NVTL & 578 & 5.01 & 446.4 & 446.3 \\
VYTV & 578 & 5.01 & 481.4 & 481.3 \\
VVTL & 643 & 5.05 & 431.3 & 431.3 \\
NVVL & 643 & 5.05 & 444.3 & 444.3 \\
VVVL & 734 & 5.05 & 429.3 & 429.3 \\
NYTF & 762 & 5.49 & 544.1 & 544.1 \\
NFTF & 1014 & 5.49 & 528.1 & 528.1 \\
FYTF & 1108 & 5.84 & 577.2 & 577.3 \\
NYFF & 1245 & 5.84 & 590.1 & 590.3 \\
NFFL & 1311 & 5.76 & 540.3 & 540.3 \\
FFTF & 1389 & 5.71 & 561.2 & 561.3 \\
NFFF & 1454 & 5.71 & 574.2 & 574.3 \\
FYFF & 1615 & 6.02 & 623.1 & 623.3 \\
FFFL & 1700 & 5.93 & 573.3 & 573.3 \\
FFFF & 1806 & 5.97 & 607.0 & 607.3 \\
\hline & & & & \\
\hline
\end{tabular}

a $m / z$ values correspond to experimental values.

${ }^{\mathrm{b}} \mathrm{m} / \mathrm{z}$ values correspond to calculated monoisotopic values calculated according to reference 5 .

\section{Summary of Peaks Observed Under Precursor Ion Conditions Across the Complete Dataset}

It is straightforward to calculate $\mathrm{m} / \mathrm{z}$ ratios for groups of sequences that are expected to be present in this library. Many of the calculated precursor ion $\mathrm{m} / \mathrm{z}$ ratios are in agreement with the values measured for the $[\mathrm{M}+\mathrm{H}]^{+}$ ions. By comparing calculated $\mathrm{m} / \mathrm{z}$ values with experimental values we are able to pick out the $[\mathrm{M}+\mathrm{H}]^{+}$ion for the 27 non-isobaric peptides having no sequence isomers. (Many of the remaining non-sequence isomer peptides are also present but are isobaric with other peptide sequences.) Table 2 is a list of these ions with their corresponding frame numbers, drift times, and $\mathrm{m} / \mathrm{z}$ ratios. This table is sorted by the frame number or elution order of the peptides. In observing the amino acid composition of these peptides, it is evident that the elution order follows what is expected for reversed phase chromatography. Peptides containing several glutamic acids, a polar amino acid, eluted first while peptides containing several phenylalanines, a non-polar amino acid, eluted later. Peptides containing several valines eluted in the middle of the LC run. These observations are expected and can help in identifying a peptide that is isobaric with another non sequence isomer peptide.

Figure 2 shows a two dimensional representation of the dataset, a plot of the $t_{R}\left[t_{D}\right]$ dimensions, which shows 


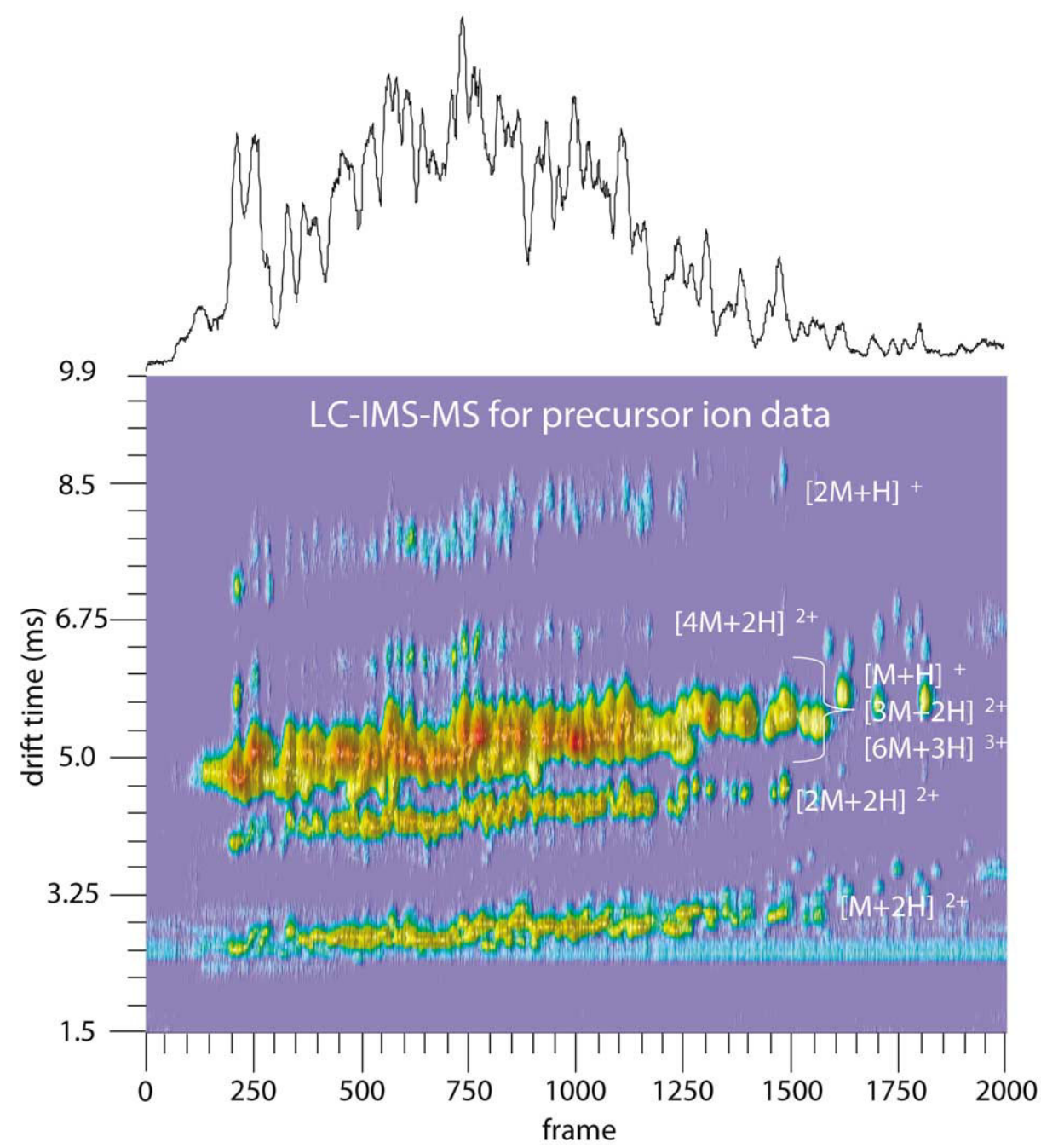

Figure 2. Contour plot of $t_{R}\left[t_{D}\right]$ of the precursor ion dataset showing separation of charge states and multimers. Each frame corresponds to $2.5 \mathrm{~s}$ of retention time in the LC run. Note the large feature toward the center of the figure is a combination of the $[\mathrm{M}+\mathrm{H}]^{+}$, the $[3 \mathrm{M}+2 \mathrm{H}]^{2+}$, and the $[6 \mathrm{M}+$ $3 \mathrm{H}]^{3+}$ that over lap in the drift time dimension. The total ion chromatogram is plotted at top of the figure.

the ability of these techniques to separate condensed and gas-phase peptides. It is instructive to consider this plot because it provides a summary of how the mobility- and LC-separations are related. These data show that the different ions that are formed fall into at least five resolvable families of peaks and that the abundances of components in some families vary across the LC-separation. Using similar considerations for the assignments that were made for frames 600,800 , and 1000 in Figure 1, it is possible to provide some rough assignments of the families that are observed. Across most of the experiments we resolve families of peaks that can be assigned to doubly-charged $[\mathrm{M}+2 \mathrm{H}]^{2+}$ tetrapeptide monomers (from $\sim 2.2$ to $2.9 \mathrm{~ms}$ ) and [2M $+2 \mathrm{H}]^{2+}$ dimers (from 3.8 to $4.7 \mathrm{~ms}$ ). The largest feature in this plot is dominated by formation of $[\mathrm{M}+\mathrm{H}]^{+}$ peptides (from $\sim 4.7$ to $5.5 \mathrm{~ms}$ ); however, we note that this feature overlaps with other higher order clusters (e.g., $[3 \mathrm{M}+2 \mathrm{H}]^{2+}$ and $[6 \mathrm{M}+3 \mathrm{H}]^{3+}$ ). Interestingly, this view of the data allows the very low intensity groups of peaks associated with formation of $[4 \mathrm{M}+2 \mathrm{H}]^{2+}$ ions to be effectively resolved from other groups of ions. The distribution of $[2 \mathrm{M}+\mathrm{H}]^{+}$dimers is also clearly resolved.

At first glance it appears that one useful analysis would be to cut through this plot along a region associated with a specific type of mobility-resolved family of ions. This would allow datasets associated with only specific charge states (e.g., $[\mathrm{M}+2 \mathrm{H}]^{2+}$ ) or cluster sizes (e.g., $[2 \mathrm{M}+\mathrm{H}]^{+}$or $[4 \mathrm{M}+2 \mathrm{H}]^{2+}$ ) to be extracted and examined. Although we have not examined these data with this approach, we are considering other systems where this analysis would be valuable. The specific advantage of this approach is that chemical noise introduced by the ESI source (from formation of mulitimers) can be effectively eliminated for some regions. 

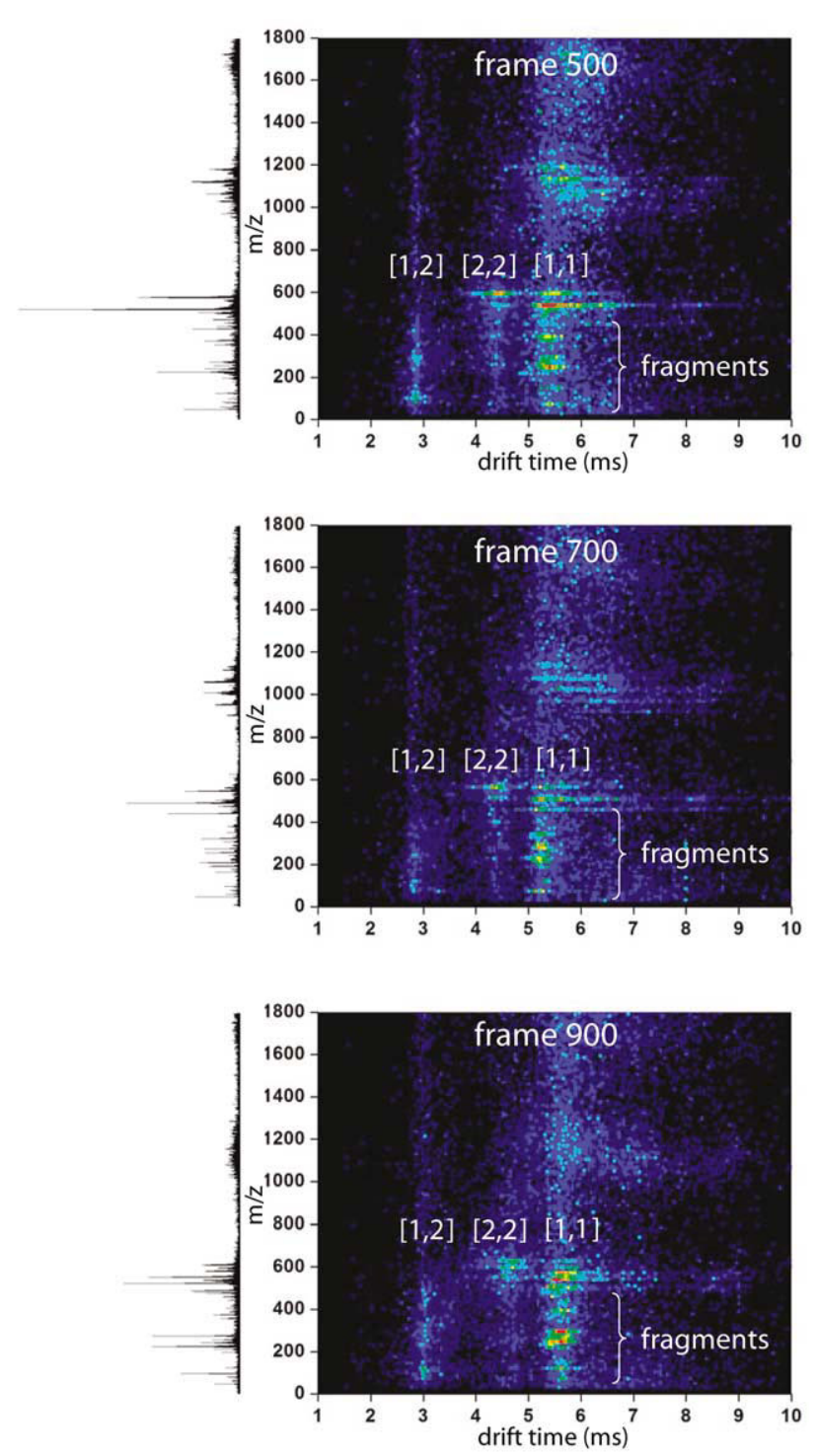

Figure 3. Three $t_{D}\left(t_{F}\right)$ plots from the fragmentation ion $t_{R}\left[t_{D}\left(t_{F}\right)\right]$ dataset. Frame $500\left(t_{R}=21.0 \mathrm{~min}\right), 700\left(t_{R}=29.4 \mathrm{~min}\right)$, and $900\left(t_{R}\right.$ $=38.0 \mathrm{~min}$ ) all show efficient fragmentation of the $[\mathrm{M}+\mathrm{H}]^{+}$ $([1,1])$ and $[2 \mathrm{M}+\mathrm{H}]^{+}([2,1])$. The $[2 \mathrm{M}+2 \mathrm{H}]^{2+}([2,2])$ shows little to no fragmentation. There are also higher mass multimers that are either fragmenting from a larger multimer or are stable through the CID process. The nomemcalture $[\mathrm{m}, \mathrm{n}]$, where $\mathrm{m}$ is the number of monomer units and $\mathrm{n}$ is the charge, is used to label the multimers.

\section{Analysis of Individual $t_{D}\left(t_{F}\right)$ Frames within the $t_{R}\left[t_{D}\left(t_{F}\right)\right]$ Dataset and a Summary of Data Recorded Under CID Conditions}

A summary of the dataset obtained upon accelerating ions into a gas-filled collision cell (i.e., CID conditions) is given in Figures 3 and 4 . Figure 3 shows three individual $t_{D}\left(t_{F}\right)$ datasets (frames 500,700 , and 900 ) that were recorded during the LC separation. Figure 4 shows a summary plot of the $t_{R}\left[t_{D}\right]$ separation. We note that currently our apparatus loses a significant fraction of signal during CID analysis. A comparison of the summary of CID data in Figure 4 with the summary of precursor ion data in Figure 2 shows that many of the low-abundance features associated with multimer formation simply disappear. We estimate that ion signals accumulated in the CID experiment are less than those for precursor ion data (at similar retention times) by factors of $\sim 5$ to 10 . Presumably ions are scattered out of the collision cell, or are defocused upon entering the TOF source. Those peaks that are observed correspond to the largest features that were apparent in the precursor ion dataset.

It is instructive to consider several of the example frames in more detail. A common feature that is observed in the CID-MS datasets in Figure 3 is the alignment of groups of peaks across the drift time dimension. That is, at a given drift time, multiple peaks corresponding to ions with different $\mathrm{m} / \mathrm{z}$ values are observed. As described previously this coincidence allows us to correlate fragments with their antecedent precursor ions. The plots of frames 500, 700, and 900 are typical of most frames across the dataset. Peaks associated with the most abundant features present in the precursor ion data (Figures 1 and 2) i.e., $[\mathrm{M}+\mathrm{H}]^{+}$and $[\mathrm{M}+2 \mathrm{H}]^{2+}$ tetrapeptide monomers and $[2 \mathrm{M}+2 \mathrm{H}]^{2+}$ dimers, show the most abundance and largest amount of dissociation in the fragment ion data.

In addition, some small peaks at higher $\mathrm{m} / \mathrm{z}$ values persist in the fragmentation data while others are not apparent. Although we do not fully understand the origin of these higher $\mathrm{m} / \mathrm{z}$ ions, we speculate two possible mechanisms for their existence. These ions could be especially stable clusters that simply persist under CID conditions. We are currently pursing this approach as a means of identifying stable aggregates. This type of approach may make it possible to identify systems with special characteristics, such as the recently discovered serine octamer cluster system [27]. Another explanation is that these clusters arise upon dissociation of larger ions that were outside of the $1800 \mathrm{~m} / \mathrm{z}$ range studied here.

\section{LC-IMS-CID-MS for Assignment of Library Components}

One of the primary goals of this work was to develop a method that allows specific peaks in multidimensional datasets to be uniquely assigned to specific sequences. Figure 5 shows a typical $t_{D}\left(t_{F}\right)$ dataset (frame $375, t_{R}=$ $15.9 \mathrm{~min}$ ) in which peptide ions that elute are separated and then exposed to energizing collisions within the collision cell prior to $\mathrm{m} / \mathrm{z}$ analysis. Under these conditions, fragment ions are located at the same drift times as the antecedent precursors from which they came. In frame 375 several peptides appear to be dissociating. Figure 5 shows two mass spectral slices through the dataset taken at $t_{D}=4.96$ and $5.34 \mathrm{~ms}$. Examination of these mass spectra show that the largest peak in the mass spectral slice obtained at $4.96 \mathrm{~ms}$ corresponds to an $[\mathrm{M}+\mathrm{H}]^{+}$ion having $\mathrm{m} / \mathrm{z}=475.2$. The largest peak 


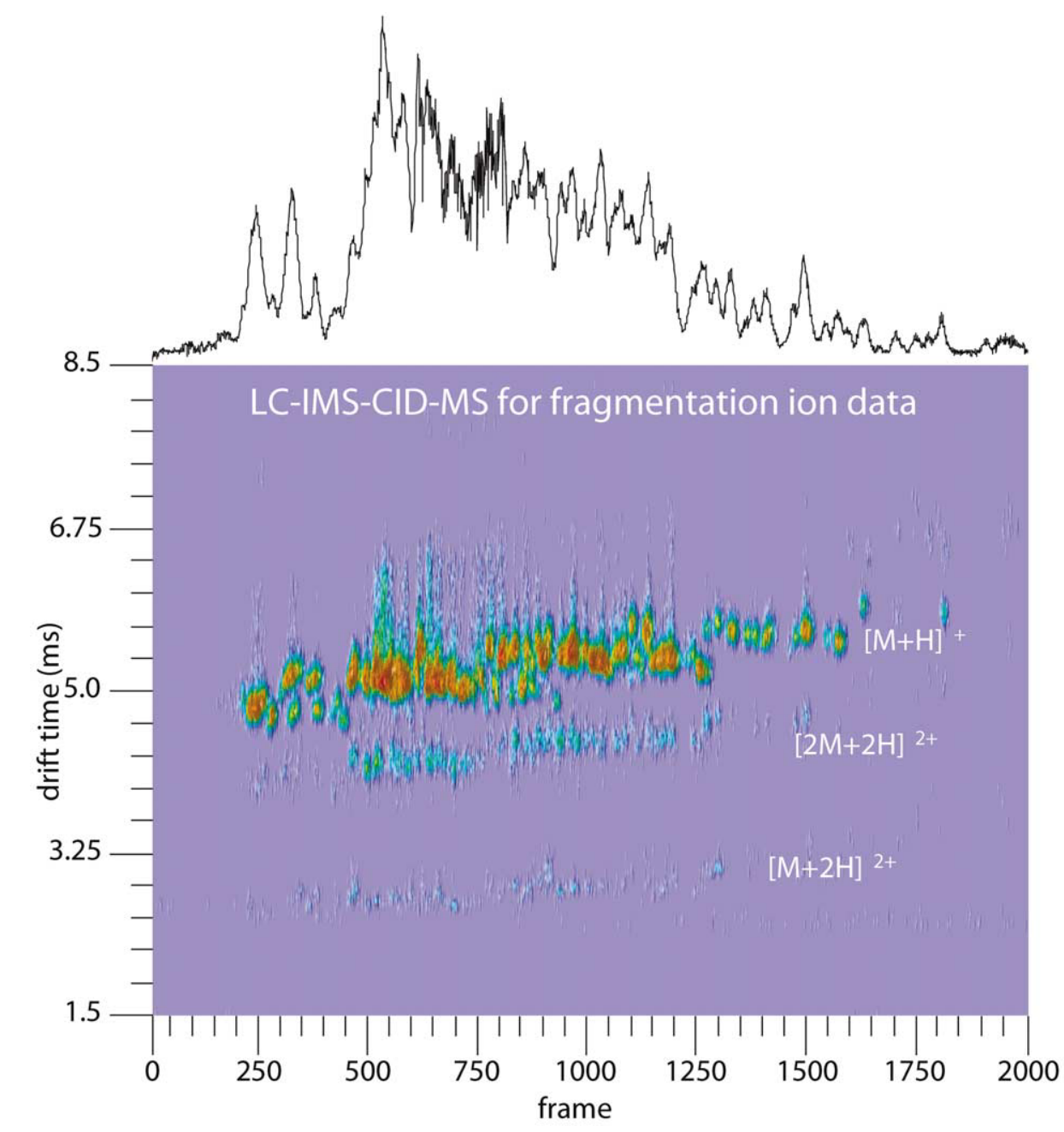

Figure 4. Contour plot of $t_{R}\left[t_{D}\right]$ of the fragment ion dataset showing separation of charge states and multimers. By comparing Figure 2 (the contour plot of $t_{R}\left[t_{D}\right]$ of the precursor ion dataset) it is clear that signal is reduced and a smaller number of features are apparent. The most distinctive features of the fragmentation ion data are the $[\mathrm{M}+\mathrm{H}]^{+},[2 \mathrm{M}+\mathrm{H}]^{+}$and $[2 \mathrm{M}+2 \mathrm{H}]^{2+}$. Fragment ions are hidden under their precursor ion in this type of plot due to the fact the fragment ions have the same $t_{D}$ and $t_{R}$ as their precursor ion. The total ion chromatogram is plotted at top of the figure.

in the slice taken at $5.34 \mathrm{~ms}$ corresponds to an $[\mathrm{M}+\mathrm{H}]^{+}$ ion with $\mathrm{m} / \mathrm{z}=539.2$. We assign these peaks to $[\mathrm{M}+$ $\mathrm{H}]^{+}$precursor ions because we find peaks in the analogous frame of the LC-IMS-TOF precursor ion data (i.e., the data shown in Figures 1 and 2). A general result of the CID conditions that we have employed is that the precursor ion peaks normally predominate.

There are six sequence isomers having $\mathrm{m} / \mathrm{z}=475.2$ as the calculated value for $[\mathrm{M}+\mathrm{H}]^{+}$: Glu-Glu-Val-Val, Glu-Val-Glu-Val, Glu-Val-Val-Glu, Val-Glu-Glu-Val, Val-Glu-Val-Glu, and Val-Val-Glu-Glu. Six additional fragment ions that are present in the mass spectral slice $a$ of Figure 5 allow us to unambiguously assign the peptide at $4.96 \mathrm{~ms}$ in frame 375 to the Val-Glu-Val-Glu isomer. Similarly, there are four $[\mathrm{M}+\mathrm{H}]^{+}$sequence isomers which are expected to at $m / z=539.2$ : Glu-TyrGlu-Val, Glu-Tyr-Val-Glu, and Val-Tyr-Glu-Glu. From the fragment ions that are observed in mass spectral slice $b$ of Figure 5 we assign can the peptide at $5.34 \mathrm{~ms}$ to the Val-Tyr-Glu-Glu sequence.

This type of analysis has been carried out for many of the frames in the complete dataset in order to provide a detailed characterization of the library. In most cases, it is possible to assign peaks that are observed to specific sequences that are anticipated to be present from the synthesis. In some cases, the fragments that are formed do not provide enough information to uniquely identity a sequence. That is, a key fragment that would be required for the unique identification simply was not detected. In these cases the fragmentation data still allow us to narrow down the number of possible sequence assignments for a specific peak. Although we have not done so here, we anticipate that calculations of mobilities for trial conformers of different sequences may help with these assignments. Because such calculations are time consuming the ability of the MS data to 

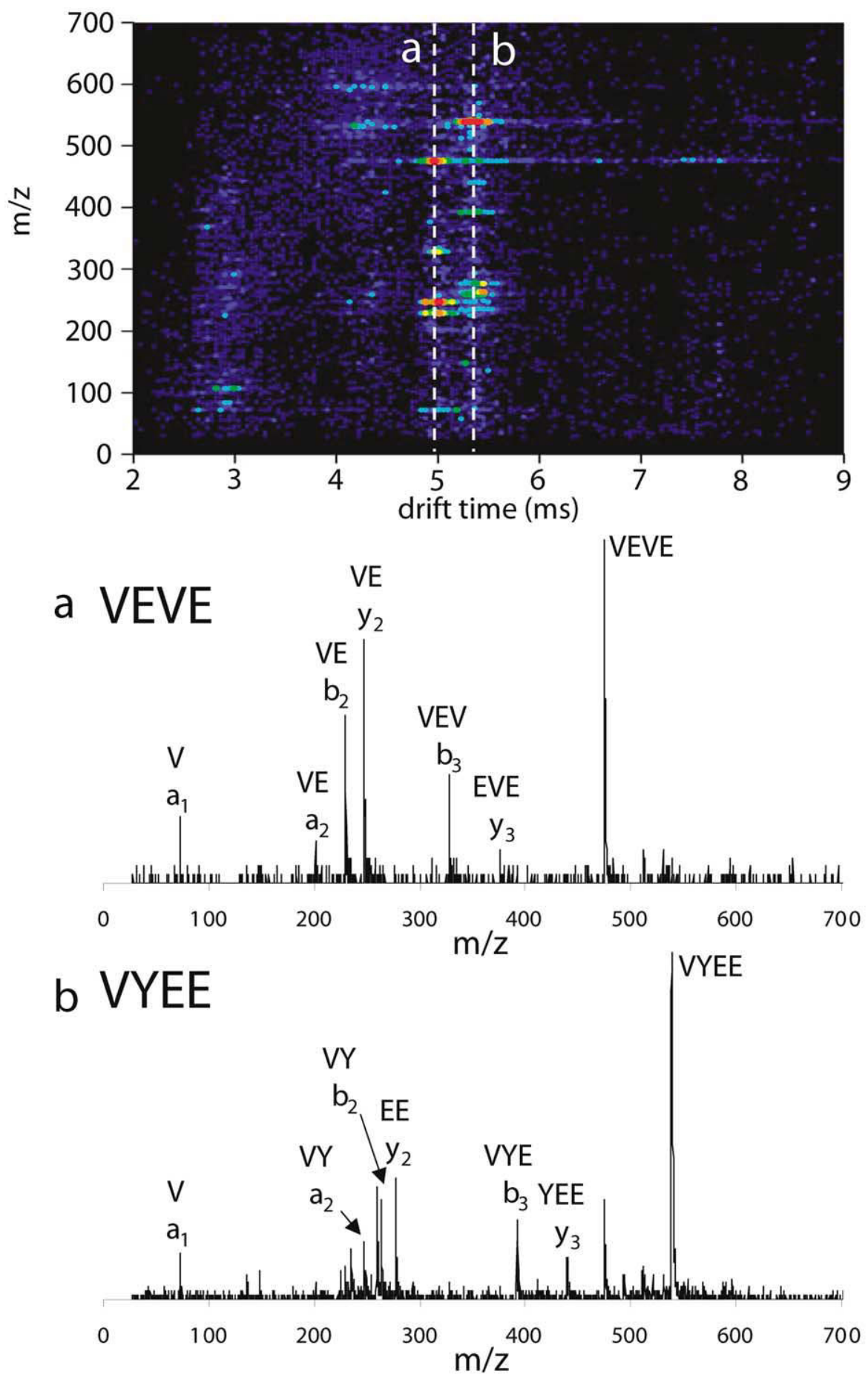

Figure 5. Fragmentation of two co-eluting peptides in LC frame number 375. Mass spectral slice $a$ shows the unique fragmentation pattern of the peptide Val-Glu-Val-Glu (VEVE) and slice $b$ show the unique fragmentation pattern of the peptide Val-Tyr-Glu-Glu (VYEE). Other sequence isomers exist in the mixture for both peptides but unique identification was possible due to the fragmentation patterns.

reduce the number of species that need to be considered is significant.

A number of features appear to be common to many frames across the CID dataset. Several aspects of these data that we find interesting can be illustrated by examining Figure 6, which shows the $t_{D}\left(t_{F}\right)$ spectra recorded for frame $880\left(t_{R}=37.2 \mathrm{~min}\right)$. At least four CID-MS spectra can be resolved-labeled in Figure 6 as $[\mathrm{M}+2 \mathrm{H}]^{2+}$, and slices $a, b$, and $c$. We point out that four CID-MS spectra are obtained in this single frame, because this illustrates the high-throughput character of this technique (four peptides assigned from data ac- 

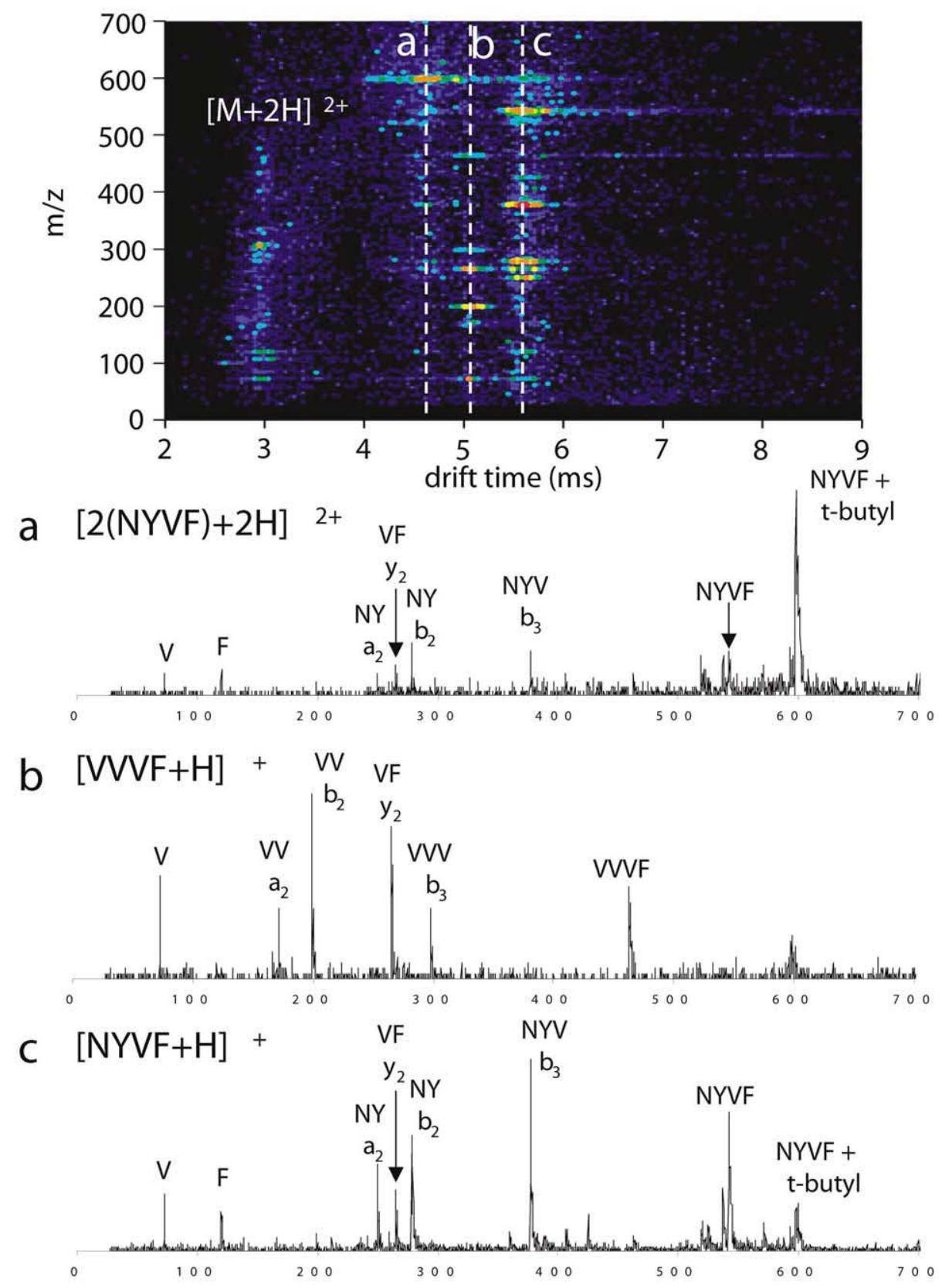

Figure 6. Mass spectral slices $a, b$, and $c$ in frame 880, can be used to uniquely identify the two co-eluting peptides, Val-Val-Val-Phe (VVVF) and Asn-Tyr-Val-Phe (NYVF). Slice a shows a dimer formed from NYVF that has a t-butyl side chain protecting group attached to the tyrosine of the peptide monomer. This dimerization tends to be dominate among peptide that contain tyrosine, and can be identified by a mass shift of $56 \mathrm{a} \mu$. This observation of dimerization in the data could be considered a marker for peptides containing tyrosine.

quired in only $2.5 \mathrm{~s}$ ). It is common to resolve three to six CID-MS spectra within an individual frame.

The assignment of peaks to specific peptide sequence from the data in Figure 6 is relatively straightforward for peak $b$. Here, the $\mathrm{m} / \mathrm{z}$ ratios for the fragments in the mass spectral slice make it possible to unambiguously assign the peptide at $5.08 \mathrm{~ms}$ as the Val-Val-Val-Phe peptide. The mass spectra obtained from slices $a$ and $c$ show more interesting behavior. These two slices show similar fragmentation patterns. Examination of the drift times of these peaks (and analogous peaks found in the precursor ion dataset) indicates that slice $a$ corresponds to dissociation of a $[2 \mathrm{M}+2 \mathrm{H}]^{2+}$ dimer and slice $c$ corresponds to dissociation of the monomer of the same peptide. In the slice $a$ case, the peptides that are ultimately identified by CID-MS have drifted through the IMS instrument in a configuration that results in a very different position in the spectrum than would be observed if they had drifted through as either $[\mathrm{M}+\mathrm{H}]^{+}$ or $[\mathrm{M}+2 \mathrm{H}]^{2+}$ species. 
We identify the $[\mathrm{M}+\mathrm{H}]^{+}$monomer and the $[2 \mathrm{M}+$ $2 \mathrm{H}]^{2+}$ dimer from the fragment masses seen in $a$ and $c$ as the Tyr-containing peptide Asn-Tyr-Val-Phe in which a t-butyl protecting group remains attached to the Tyr residue. We note that throughout the CID dataset it appears that modified Tyr-containing peptides appear to preferentially be observed as $[2 \mathrm{M}+$ $2 \mathrm{H}]^{2+}$ dimers. That is, dimer formation appears to be favored for these peptides relative to others. As we analyzed the CID dataset in detail, mass spectral slices associated with mobility separation of ions as $[2 \mathrm{M}+$ $2 \mathrm{H}]^{2+}$ dimers became a signature for the modified Tyr residue containing peptides.

\section{Evidence for a Synthetic Failure}

Identification of the peptide fragments and precursor ions in slices $a$ and $c$ provide an important clue about a synthetic step of the synthesis that did not proceed as expected. Both CID datasets are consistent with the Asn-Tyr-Val-Phe having a precursor ion that has been modified by a chemical group that shifts the mass by 56 a $\mu$. We have previously identified this mass shift as evidence that a t-butyl side chain protecting group is not completely removed during the final deprotection steps of the synthesis [6]. Examination of many frames in the mixture indicates that greater than $90 \%$ of peptides containing a Tyr in the sequence exhibit this 56 a $\mu$ shift in the precursor ion mass. A smaller fraction of peptides containing a Glu residue may also be influenced by this synthetic failure.

\section{Utility of Separating Ions as Complexes}

Finally we note that the ability to separate ions as non-covalent complexes in the gas phase prior to identification by CID-MS suggests some interesting new approaches for varying the relative positions of ions within mobility separations of mixtures. [We note that covalent binding interactions could also be designed to shift mobilities in specific ways.] In many cases peaks found in ion mobility data are not fully resolved - and attempts to vary the positions of peaks by changing the buffer gas composition have had only limited success [28]. It seems likely that specific non-covalent complexes could be formed and separated in the drift tube and then subjected to energizing collisions in order to produce fragments that would identify precursor ions.

At first consideration, the idea of shifting mobilities by the formation of non-covalent complexes might seem to be an extension of many early results that can be found in the IMS literature that involve the formation of water (or other small molecule) adducts in the gas phase [29]. However the application of this approach for shifting the mobilities of peptide ions may have interesting advantages. Recently, Julian and Beauchamp have reported that crown ethers bind selectively to Lys residues of peptides and proteins (in solution) and are retained in the gas phase [30]. Thus, one can imagine forming peptide-crown complexes in order to shift the mobilities of Lys-containing peptides away from non-Lys containing peptides (that would normally have similar mobilities). We are currently investigating this approach as a means of influencing the mobility separation [31].

\section{Summary and Conclusions}

The work described here is the first to explore the use of combined LC/IMS/MS and LC/IMS/CID/MS techniques for the analysis of a combinatorial peptide library. The library that we examined is expected to contain 256 different tetrapeptide sequences. The peptides that were expected to be present are described by the general form $\mathrm{Xxx}_{1}-\mathrm{Xxx}_{2}-\mathrm{Xxx}_{3}-\mathrm{Xxx}_{4}$ where $\mathrm{Xxx}_{1}=$ Glu, Phe, Val, Asn; $X x_{2}=$ Glu, Phe, Val, Tyr; $X x_{3} x_{3}=$ Glu, Phe, Val, Thr; and $X x_{4}=$ Glu, Phe, Val, Leu. This system was designed to create a range of complexity associated with sequence isomers: including 46 peptides that have no sequence isomer counterparts; 18 sets of two sequence isomers; 24 sets of three sequence isomers; six sets of four sequence isomers; seven sets of six sequence isomers; and, three sets of 12 .

Analysis of this system under conditions that favor the precursor ions (an LC-IMS-MS approach) showed evidence for formation of $[\mathrm{M}+\mathrm{H}]^{+}$and $[\mathrm{M}+2 \mathrm{H}]^{2+}$ precursor ions as well as an array of multiply-charged multimers (present in relatively low abundances). Under conditions where the mobility separated ions are exposed to energizing collisions in the octopole collision cell few multimers survive and the datasets are dominated by fragments that can be assigned to [M + $\mathrm{H}^{+}$and $[\mathrm{M}+2 \mathrm{H}]^{2+}$ monomers as well as doublycharged dimers $\left([2 \mathrm{M}+2 \mathrm{H}]^{2+}\right.$ species $)$.

The observation of fragment ions from $[2 \mathrm{M}+2 \mathrm{H}]^{2+}$ precursors is interesting for a number of reasons. First, it appears that tyrosine containing peptides may favor the formation of multimers. In the present system, the tyrosine containing peptides appear to be modified by a $\mathrm{t}$-butyl group that is used to protect the side chain during synthesis. In this case, it appears that the deprotection chemistry has not proceeded as expected. The preferential formation of $[2 \mathrm{M}+2 \mathrm{H}]^{2+}$ ions for $\mathrm{t}$ butylated tyrosine containing peptides provides a means of rapidly identifying these peptides. In this case, these peptides are anticipated to be present when peaks corresponding to fragmentation of $[2 \mathrm{M}+2 \mathrm{H}]^{2+}$ ions are observed in LC-IMS-CID-MS data. The highermobilities of doubly-charged dimers relative to [M + $\mathrm{H}]^{+}$ions can effectively be used as a signature for these ions. The ability to rapidly pick out steps in combinatorial library synthetic strategies that do not proceed as anticipated is of great interest for the development of mix and split strategies.

An important aspect of the present work is the ability to carry out fragmentation processes for mixtures of ions in parallel. This makes it possible to rapidly examine mixtures of co-eluting peptides. This work 
provided several examples in which CID-MS data was used to uniquely assign peptide sequences that were isomeric with other peptides in the library mixture. In these studies, it was possible to collect useful CID-MS information for up to $\sim 6$ different ions during the $2.5 \mathrm{~s}$ acquisition time associated with the acquisition of individual $t_{D}\left(t_{F}\right)$ frames. The ability to assign specific isomer sequences in complex mixtures is clearly important in many areas of study, such as drug discovery. We note that although this approach works for this simple system, more complex libraries may show regions where the fragmentation data alone cannot be used to unambiguously assign peptide sequences. In this case, we anticipate that the fragmentation data will be useful for reducing the number of possible sequences that would need to be examined by comparing calculated cross sections for trial conformations.

Finally, although screening strategies were not the focus of this paper, we note that this approach should facilitate new on-line screening strategies. Targets could be introduced immediately after the separation step (just prior to electrospraying mixtures into the drift tube). Favorable ligand-substrate interactions would result in complexes that would be shifted into a different region of the IMS separation. By then subjecting these complexes and non-bound ligands to CID, binding ligands would be fragmented and identified in a different region of the spectra than the non-bound ligands. Efforts to develop this approach as a means of screening well defined libraries against specified targets are currently underway in our laboratory.

\section{Acknowledgments}

This work is supported by a grant from the National Institutes of Health (1R01GM-59145-03). The authors acknowledge Dr. Xinfeng Gao and C. Ray Sporleder for their help in the visualization and analysis of these data.

\section{References}

1. (a) Merrifield, B. Solid Phase Synthesis. Science 1986, 232, 341-347. (b) Epton, R. Innovation and Perspectives in Solid Phase Synthesis, Vol III; Mayflower Worldwide Ltd: Birmingham, 1994. (c) Lebl, M.; Krchnak, V. Synthetic Peptide Libraries. Methods Enzymol 1997, 289, 336-392.

2. (a) Chu, Y.-H.; Dunayevskiy, Y. M.; Kirby, D. P.; Vouros, P.; Karger, B. L. Affinity Capillary Electrophoresis-Mass Spectrometry for Screening Combinatorial Libraries. J. Am. Chem. Soc 1996, 118, 7827-7835. (b) Loo, J. A. Mass Spectrometry in the Combinatorial Chemistry Revolution. Eur. Mass Spectrom 1997, 3, 93-104. (c) Dunayevskiy, Y. M.; Lai, J.-J.; Quinn, C.; Talley, F.; Vouros, P. Mass Spectrometric Identification of Ligands Selected from Combinatorial Libraries Using Gel Filtration. Rapid Commun. Mass Spectrom 1997, 11, 11781184. (d) Wigger, M.; Nawrocki, J. P.; Watson, C. H.; Eyler, J. R.; Benner, S. A. Assessing Enzyme Substrate Specificity Using Combinatorial Libraries and Electrospray IonizationFourier Transform Ion Cyclotron Resonance Mass Spectrometry. Rapid Commun. Mass Spectrom. 1997, 11, 17491752. (e) Wieboldt, R.; Zweigenbaum, J; Henion, J. Immunoaffinity Ultrafiltration with Ion Spray HPLC/MS for
Screening Small-Molecule Libraries. Anal. Chem. 1997, 69, 1683-1691. (f) Nawrocki, J. P.; Wigger, M.; Watson, C. H.; Hayes, T. W.; Senko, M. W.; Benner, S. A.; Eyler, J. R. Analysis of Combinatorial Libraries Using Electrospray Fourier Transform Ion Cyclotron Resonance Mass Spectrometry. Rapid Commun. Mass Spectrom. 1996, 10, 1860-1864. (g) Metzger, J. W.; Kempter, C.; Wiesmuller, K. H.; Jung, G. Electrospray Mass Spectrometry and Tandem Mass Spectrometry of Synthetic Multicomponent Peptide Mixtures: Determination of Composition and Purity. Anal. Biochem. 1994, 219, 261277. (h) Lambert, P-.H.; Boutin, J. A.; Bertin, S.; Fauchére, J.-L.; Volland, J.-P. Evaluation of High Performance Liquid Chromatography/Electrospray Mass Spectrometry with Selected Ion Monitoring for the Analysis of Large Synthetic Combinatorial Peptide Libraries. Rapid Commun. Mass Spectrom. 1997, 11, 1971-1976. (i) Rozenski, J.; Chaltin, P.; Van Aerschot, A.; Herdewijn, P. Characterization and Sequence Confirmation of Unnatural Amino Acid Containing Peptide Libraries Using Electrospray Ionization Mass Spectrometry. Rapid Commun. Mass Spectrom. 2002, 16, 982-987. (j) Kassel, D. B. Combinatonial Chemistry and Mass Spectrometry in the 21st Century Drug Discovery Laboratory. Chem. Rev. 2001, 101, 255267. (k) Wang, P.; Snarvley, D. F.; Freitas, M. A.; Pei, D. Screening Combinatorial Libraries for Optimal Enzyme Substrates by Mass Spectrometry. Rapid Commun. Mass Spectrom. 2001, 15, 1166-1171.

3. Fenn, J. B.; Mann, M.; Meng, C. K.; Wong, S. F.; Whitehouse, C. M. Electrospray Ionization for Mass Spectrometry of Large Biomolecules. Science 1989, 246, 64-71.

4. (a) Constantine, G. Combinatorial Theory and Statistical Design; John Wiley and Sons: New York, 1987. (b) Demirev, P. A.; Zubarev, R. A. Probing Combinatorial Library Diversity by Mass Spectrometry. Anal. Chem. 1997, 69, 2893-2900.

5. Available at http://prowl.rockefeller.edu/ (2003).

6. Srebalus, C. A.; Li, J.; Marshall, W. S.; Clemmer, D. E. Gas-Phase Separations of Electrosprayed Peptide Libraries. Anal. Chem. 1999, 71, 3918-3927.

7. Srebalus, C. A.; Li, J.; Marshall, W. S.; Clemmer, D. E. Determining Synthetic Failures in Combinatorial Libraries by Hybrid Gas-Phase Separation Methods. J. Am. Soc. Mass Spectrom. 2000, 11, 352-355.

8. Srebalus Barnes, C. A.; Clemmer, D. E. Assessment of Purity and Screening of Peptide Libraries by Nested Ion MobilityTOFMS: Identification of RNase S-Protein Binders. Anal. Chem. 2001, 73, 424-433.

9. Srebalus Barnes, C. A.; Hilderbrand, A. E.; Valentine, S. J.; Clemmer, D. E. Resolving Isomeric Peptide Mixtures: A Combined HPLC/Ion Mobility-TOFMS Analysis of a 4000 Component Combinatorial Library. Anal. Chem. 2002, 74, 26-36.

10. (a) St. Louis, R. H.; Hill, H. H., Jr. Ion Mobility Spectrometry in Analytical Chemistry. Crit. Rev. Anal. Chem. 1990, 21, 321355. (b) Clemmer, D. E.; Jarrold, M. F. Ion Mobility Measurements and Their Applications to Clusters and Biomolecules. J. Mass Spectrom 1997, 32, 577-592. (c) Liu, Y.; Valentine, S. J.; Counterman, A. E.; Hoaglund, C. S.; Clemmer, D. E. InjectedIon Mobility Analysis of Biomolecules. Anal. Chem. 1997, 69, 728A-735A.

11. Mason, E. A.; McDaniel, E. W. Transport Properties of Ions in Gases; Wiley: New York, 1988.

12. (a) von Helden, G.; Hsu, M.-T.; Kemper, P. R.; Bowers, M. T. Structures of Carbon Cluster Ions from 3 to 60 Atoms: Linears to Rings to Fullerenes. J. Chem. Phys. 1991, 95, 38353837. (b) Jarrold, M. F.; Constant, V. A. Silicon Cluster Ions: Evidence for a Structural Transition. Phys. Rev. Lett 1991, 67, 2994-2997. (c) Clemmer, D. E.; Hudgins, R. R.; Jarrold, M. F. Naked Protein Conformations: Cytochrome $c$ in the Gas Phase. J. Am. Chem. Soc 1995, 117, 10141-10142. 
13. Wittmer, D.; Chen, Y.-H.; Luckenbill, B. K.; Hill, H. H., Jr. Electrospray Ionization Ion Mobility Spectrometry. Anal. Chem. 1994, 66, 2348-2355.

14. (a) von Helden, G.; Kemper, P. R.; Gotts, N. G.; Bowers, M. T. Isomers of Small Carbon Cluster Anions: Linear Chains with up to 20 Atoms. Science 1993, 259, 1300-1302. (b) Wittmer, D.; Chen, Y.-H.; Luckenbill, B. K.; Hill, H. H., Jr. Electrospray Ionization Ion Mobility Spectrometry. Anal. Chem. 1994, 66, 2348-2355. (c) von Helden, G.; Wyttenbach, T.; Bowers, M. T. Conformation of Macromolecules in the Gas Phase: Use of Matrix-Assisted Laser Desorption Methods in Ion Chromatography. Science 1995, 267, 1483-1485. (d) Clemmer, D. E.; Jarrold, M. F. Ion Mobility Measurements and Their Applications to Clusters and Biomolecules. J. Mass Spectrom 1997, 32, 577-592. (e) Shvartsburg, A. A.; Schatz, G. C.; Jarrold, M. F. Mobilities of Carbon Cluster Ions: Critical Importance of the Molecular Attractive Potential. J. Chem. Phys. 1998, 108, 24162423. (f) Baumbach, J. I.; Eiceman, G. A. Ion Mobility Spectrometry: Arriving on Site and Moving Beyond a Low Profile. Appl. Spectrosc. 1999, 53, 338A-355A.

15. Wu, C.; Siems, W. F.; Klasmeier, J.; Hill, H. H., Jr. Separation of Isomeric Peptides Using Electrospray Ionization/HighResolution Ion Mobility Spectrometry. Anal. Chem. 2000, 72, 391-395.

16. Hoaglund, C. S.; Valentine, S. J.; Clemmer, D. E. An Ion Trap Interface for ESI-Ion Mobility Experiments. Anal. Chem. 1997, 69, 4156-4161.

17. Myung, S.; Lee, Y.-J.; Moon, M.-H.; Taraszka, J. A.; Sowell, R.; Koeniger, S.; Hilderbrand, A. E.; Valentine, S. J.; Cherbas, L.; Cherbas, P.; Kaufmann, T. C.; Miller, D. F.; Mechref, Y.; Novotny, M. V.; Ewing, M.; Clemmer, D. E. Development of High-Sensitivity Ion Trap-IMS-TOF Techniques: A HighThroughput Nano-LC/IMS/TOF Separation of the Drosophila Fly Proteome, unpublished.

18. Lee, Y.-J.; Hoaglund-Hyzer, C. S.; Taraszka, J. A.; Zientara, G. A.; Counterman, A. E.; Clemmer, D. E. Collision-Induced Dissociation of Mobility-Separated Ions Using an OrificeSkimmer Cone at the Back of a Drift Tube. Anal. Chem. 2001, 73, 3549-3555.

19. Lebl, M.; Krchnak, V. Synthetic Peptide Libraries. Methods Enzymol. 1997, 289, 336-392.

20. Wellings, D. A.; Atherton, E. Standard Fmoc Protocols. Methods Enzymol. 1997, 289, 44-67.
21. Sarin, V. K.; Kent, S. B. H.; Tam, J. P.; Merrifield, R. B. Quantitative Monitoring of Solid-Phase Peptide Synthesis by the Ninhydrin Reaction. Anal. Biochem. 1981, 117, 147-157.

22. Lee, Y.-J.; Hoaglund-Hyzer, C. S. Srebalus; Barnes, C. A.; Hilderbrand, A. E.; Valentine, S. J.; Clemmer, D. E. Development of High-Throughput Liquid Chromatography Injected Ion Mobility Quadrupole Time-of-Flight Techniques for Analysis of Complex Peptide Mixtures. J. Chromatogr. B 2002, 782, 343-351.

23. Hoaglund-Hyzer, C. S.; Li, J.; Clemmer, D. E. Mobility Labeling for Parallel CID of Ion Mixtures. Anal. Chem. 2000, 72, 2737-2740.

24. Hoaglund-Hyzer, C. S.; Clemmer, D. E. Ion Trap/Ion Mobility/Quadrupole/Time-of-Flight Mass Spectrometry for Peptide Mixture Analysis. Anal. Chem. 2001, 73, 177-184.

25. Counterman, A. E.; Hilderbrand, A. E. Srebalus; Barnes, C. A.; Clemmer, D. E. Formation of Peptide Aggregates During ESI: Size, Charge, Composition, and Contributions to Noise. J. Am. Soc. Mass Spectrom. 2001, 12, 1020-1035.

26. Counterman, A. E.; Valentine, S. J.; Srebalus, C. A.; Henderson, S. C.; Hoaglund, C. S.; Clemmer, D. E. High-Order Structure and Dissociation of Gaseous Peptide Aggregates that are Hidden in Mass Spectra. J. Am. Soc. Mass Spectrom. 1998, 9, 743-759.

27. (a) Cooks, R. G.; Zhang, D.; Koch, K. J.; Gozzo, F. C.; Eberlin, M. N. Chiroselective Self-Directed Octamerization of Serine: Implications for Homochirogenesis. Anal. Chem 2001, 73, 3646-3655. (b) Counterman, A. E.; Clemmer, D. E. Magic Number Clusters of Serine in the Gas Phase. J. Phys. Chem. B 2001, 105, 8092-8096. (c) Julian, R. R.; Hodyss, R.; Kinnear, B.; Jarrold, M. F.; Beauchamp, J. L. Nanocrystalline Aggregation of Serine Detected by Electrospray Ionization Mass Spectrometry: Origin of the Stable Homochiral Gas-Phase Serine Octamer. J. Phys. Chem. B 2002, 106, 1219-1228.

28. Asbury, G. R.; Hill, H. H., Jr. Using Different Drift Gases to Change Separation Factors $(\alpha)$ in Ion Mobility Spectrometry. Anal. Chem. 2000, 72, 580-584.

29. Cohen, M. J.; Karasek, F. W. Plasma Chromatography TMNew Dimension for Gas Chromatography and Mass Spectrometry. J. Chromatogr. Sci. 1970, 8, 330-337.

30. Julian, R. R.; Beauchamp, J. L. Site Specific Sequestering and Stabilization of Charge in Peptides by Supramolecular Adduct Formation with 18-Crown-6 Ether by Way of Electrospray Oonization. Int. J. Mass Spectrom. 2001, 210/211, 613-623.

31. Hilderbrand, A. E.; Clemmer, D. E. unpublished. 